\title{
Isothermal martensite formation at sub-zero temperatures
}

\author{
Stojko, Allan; Hansen, Mikkel Fougt; Slycke, Jan; Somers, Marcel A. J.
}

Published in:

18. IFHTSE congress

Publication date:

2010

Link back to DTU Orbit

Citation (APA):

Stojko, A., Hansen, M. F., Slycke, J., \& Somers, M. A. J. (2010). Isothermal martensite formation at sub-zero temperatures. In 18. IFHTSE congress ANAIS / Proceedings

\section{General rights}

Copyright and moral rights for the publications made accessible in the public portal are retained by the authors and/or other copyright owners and it is a condition of accessing publications that users recognise and abide by the legal requirements associated with these rights.

- Users may download and print one copy of any publication from the public portal for the purpose of private study or research.

- You may not further distribute the material or use it for any profit-making activity or commercial gain

- You may freely distribute the URL identifying the publication in the public portal

If you believe that this document breaches copyright please contact us providing details, and we will remove access to the work immediately and investigate your claim. 


\title{
ISOTHERMAL MARTENSITE FORMATION AT SUB-ZERO TEMPERATURES ${ }^{1}$
}

\author{
Allan Stojko ${ }^{2}$ \\ Mikkel F. Hansen ${ }^{3}$ \\ Jan Slycke \\ Marcel A.J. Somers
}

\begin{abstract}
Sub-zero treatment of steels with an $\mathrm{M}_{\mathrm{f}}$ below zero degrees Celsius relies (partly) on a continuation of the martensite formation. The present work reports on the observation of isothermal martensite formation in the sub-zero temperature regime for two steels: AISI 1070 and AISI 52100. Samples were austenitized and quenched in oil and thereafter investigated with vibrating sample magnetometry, which allows a quantitative assessment of the fraction of retained austenite as a function of the subzero temperature and time. Isothermal martensite formation was observed on interrupting the continuous cooling $(5 \mathrm{~K} / \mathrm{min})$ with vibrating sample magnetometry at several temperatures in the range $80-233 \mathrm{~K}$. The kinetics of isothermal martensite formation depends strongly on the temperature. Similar isothermal experiments with dilatometry indicated the occurrence of volume increase on isothermal holding, consistent with a continuation of the martensitic transformation. On prolonged isothermal holding a volume reduction was observed for AISI 52100, but not for AISI 1070. A mechanism is proposed that explains the occurrence of isothermal martensite formation.
\end{abstract}

Keywords: Sub-zero treatment; Isothermal martensite; Magnetometry; Dilatometry.

Technical contribution to the $18^{\text {th }}$ IFHTSE Congress - International Federation for Heat Treatment and Surface Engineering, 2010 July 26-30 ${ }^{\text {th }}$, Rio de Janeiro, RJ, Brazil.

Formerly at Technical University of Denmark, Department of Manufacturing Engineering and Management.

Technical University of Denmark, Department of Micro- and Nanotechnology.

Formerly at SKF Engineering \& Research Centre, Nieuwegein, The Netherlands.

Technical University of Denmark, Department of Mechanical Engineering. 


\section{INTRODUCTION}

Conventional heat treatment of ball bearing steel includes austenitisation, quenching and tempering, and results in hardening and improved wear performance of the treated material. ${ }^{[1,2]}$ Traditionally, ball bearing steel is tempered at a relatively low temperature $(433 \mathrm{~K})$ rendering retained austenite regions within the tempered martensitic matrix. ${ }^{[3]}$ The presence of retained austenite is considered a limitation of the conventional heat treatment, since it can transform isothermally into martensite or upon mechanical loading during use. If a more homogeneous martensitic microstructure were present in the as-heat treated material a hardness increase and an improved dimensional stability during use would be obtained.

Sub-zero treatment (referring to the Celsius scale) of high carbon bearing steels has been claimed to have a positive effect on various mechanical properties such as wear resistance, hardness, yield strength, and dimensional and microstructural stability $^{[1,4,5]}$ due to transformation of retained austenite into martensite and in collaboration with fine carbide precipitation. ${ }^{[1,4-10]}$

AISI E 52100 (DIN 100Cr6) is widely used as a ball bearing steel. The steel is included in the group of high-carbon bearing steels, which are used in a throughhardened condition or in a surface-induction-hardened condition in a special integral bearing configuration, for instance in an automotive wheel spindle. Investigations of $100 \mathrm{Cr} 6$ regarding the influence on microstructure and transformation of retained austenite during a cryogenic treatment have been performed by various authors. ${ }^{[9,11]}$ $\mathrm{Hsu}$, et al. ${ }^{[10]}$ showed that during isothermal holding at a temperature below $\mathrm{M}_{\mathrm{s}}$, but above zero Celsius, both growth of previously nucleated martensite as well as nucleation of new martensite in austenite occurred.

In the present work sub-zero Celsius investigation of the isochronous and isothermal transformation of retained austenite into martensite was carried out with vibrating sample magnetometry (VSM) and dilatometry. Both AISI E 52100 and 1070 LS were examined.

\section{EXPERIMENTAL}

The materials applied in this investigation were ball bearing steel AISI 52100 (DIN 100Cr6) and a low-alloyed carbon steel AISI 1070 LS with the chemical compositions as given in Table 1.

Table 1. The chemical compositions of AISI 52100 (DIN 100Cr6) and AISI 1070 LS (in wt\%)

\begin{tabular}{lcccccc}
\hline Alloy & C \% & Si \% & Mn \% & $\mathrm{Cr} \%$ & Mo \% & Ni \% \\
\hline 52100 & 1.0 & 0.27 & 0.29 & 1.41 & 0.05 & 0.17 \\
1070 & 0.694 & 0.23 & 1.02 & 0.09 & 0.02 & \\
\hline
\end{tabular}

\subsection{Vibrating Sample Magnetometry (VSM)}

A Lake Shore 7400 VSM (model 736 VSM controller, with a Temperature Controller 340) equipped with a low temperature cryostat was employed. The samples applied in the VSM experiments were cylindrical $\varnothing 3.0 \mathrm{~mm}$ and $4.0 \mathrm{~mm}$ in length and were mounted onto the rigid fiber pole using non-magnetic Kapton tape.

The samples were heat treated prior to the VSM studies. Austenitization of the samples was performed in a standard glass tube furnace for 30 minutes at $1173 \mathrm{~K}$ in 
an inert atmosphere of $99.999 \%$ Ar. The samples were quenched in oil $(323 \mathrm{~K})$ for less than $30 \mathrm{~s}$, followed by cooling to ambient temperature in water. After quenching, a fixed (storing) time interval of 30 minutes at room temperature separated quenching and subsequent measurement. This fixed storage time was necessary to control the extent of isothermal transformation at room temperature, so the same austenite content is present in the investigated samples on starting the sub-zero investigation.

In the VSM, the evolution of the saturation magnetization, $\sigma_{s}(C)$, was measured as a function of temperature and/or time in an applied magnetic flux density of 1.6 Tesla $(=16 \mathrm{kG})$; the measurement time was 2 seconds per step. The strength of the magnetic field is not considered high enough to bring about significant austeniteto-martensite transformation (cf.). ${ }^{[12]}$ For non-isothermal (isochronous) continuous cooling and heating measurements the temperature step-size was $0.5 \mathrm{~K}$ and the effective cooling and heating rate was $5 \mathrm{~K} / \mathrm{min}$. The isothermal austenite-tomartensite transformation was investigated at various sub-zero temperatures by interrupting the isochronous cooling, while keeping the sample for 1 hour at the chosen temperature.

To unravel the effect of the austenite-to-martensite transformation from the total change in saturation magnetization occurring during cooling/heating at sub-zero Celsius temperature, a baseline was subtracted. The baselines for heating and cooling cycles were obtained from a (third) cycle within the temperature region under investigation after all transformations were completed in two earlier cycles. The uncertainty on the absolute measurements of the specific magnetization in the VSM was estimated to $\pm 0.7 \%$. However, the uncertainty on relative measurements on the same sample after mounting was significantly lower than $0.1 \%$.

\subsection{Dilatometry}

Two dilatometers were applied in the present investigations. A dilatometer of type Bähr 805 A/D was used to monitor the dilations of samples during austenitization, quenching and cold treatment. The lower temperature limit of this dilatometer was $185 \mathrm{~K}$. Cooling to temperatures as low as $78 \mathrm{~K}$ was carried out in an Adamel LK02 type dilatometer. The sample geometries in the two dilatometers were different:

- Bähr 805 A/D: cylindrical specimens $\varnothing 3 \mathrm{~mm}$ and $7 \mathrm{~mm}$ in length;

- Adamel LK02: tube specimen with outer $\varnothing 1.5 \mathrm{~mm}$, inner $\varnothing 1.1 \mathrm{~mm}$ and $13 \mathrm{~mm}$ in length.

The heat treatment of the samples prior to the low temperature experiments followed the same procedure as that of the VSM experiments described in section 2.1., albeit the heat treatment was carried out in the (quenching) dilatometer. After quenching, a fixed time interval of 30 minutes at room temperature was applied before commencing the sub-zero experiments (cf. section 2.1.).

The dilatation curves measured were not baseline corrected, but were normalized with respect to the length of the samples in order to allow comparison of results obtained on the two dilatometers. 


\section{RESULTS}

\subsection{Magnetometry}

The measured saturation magnetization, $\sigma_{s}(C)$, was converted into the fraction of retained austenite, $f_{\gamma}$, from:

$$
f_{\gamma}=\frac{\sigma_{S}^{a}-\sigma_{S}(C)}{\sigma_{S}^{a}}
$$

where $\sigma_{s}^{a}$ is the saturation magnetization of an austenite-free sample (the baseline) and saturation $\sigma_{s}(C)$ is the actual saturation magnetization of the sample, which depends on the carbon content in the ferromagnetic martensitic matrix.

The evolution of the fraction of retained austenite in both steels as derived from the saturation magnetization values during isochronal cooling and heating are shown in Fig.1. The solid curves for cooling experiments down to $100 \mathrm{~K}$ and $80 \mathrm{~K}$ for AISI 1070 LS and AISI E 52100, respectively, clearly show that austenite transforms into martensite during cooling as well as during heating. Evidently, the transformation rate at these low temperatures is low as follows from the slope of the curves at the lowest reached temperature. The discontinuities observed during holding for one hour at five different temperatures, as shown in Fig.1, illustrate that the transformation continues on isothermal holding. The maximum transformation rates during isochronal cooling (solid curves) are observed at $206 \mathrm{~K}$ and $190 \mathrm{~K}$ for AISI 1070 LS (Fig.1a) and 52100 (Fig.1b), respectively. During isochronal heating the maximum transformation rate is observed at $169 \mathrm{~K}$ for both materials. It is noted that during heating after isothermal holding at a temperature higher than this level $(169 \mathrm{~K})$, only a small fraction of austenite is transformed into martensite (Fig.1).

The change in austenite content during isothermal holding is shown in Fig.2. For all investigated temperatures higher than 100K, the isothermal transformation rate decreases gradually with time. Evidently, the isothermal transformation is not completed after $1 \mathrm{~h}$; indeed measurements for both steels at $193 \mathrm{~K}$ (not included here) showed that completion was not reached after $2 \mathrm{~h}$ of isothermal holding, either. ${ }^{[13]} \mathrm{A}$ peculiar effect is observed at the lowest reached temperature for AISI 1070. It appears that during isothermal holding at $100 \mathrm{~K}$ the austenite content increases. Since this is considered impossible the effect is ascribed to experimental uncertainties. 


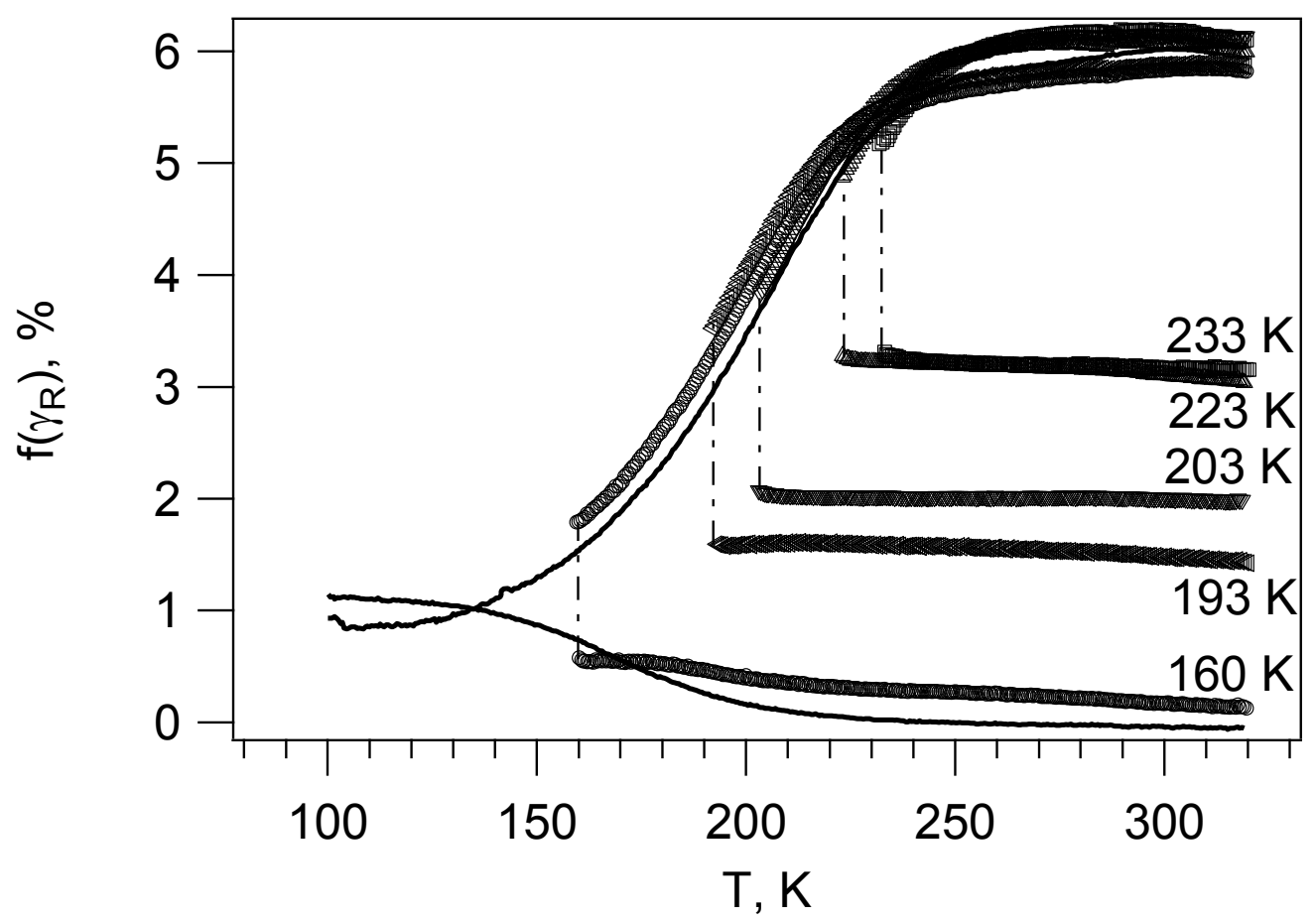

Figure 1a. Fraction of retained austenite in AISI 1070. The vertical dash-dot lines mark the temperature where isothermal holding for $1 \mathrm{~h}$ was investigated (see Fig. 2a). The upper curves are the cooling curves; the lower curves are the heating curves.

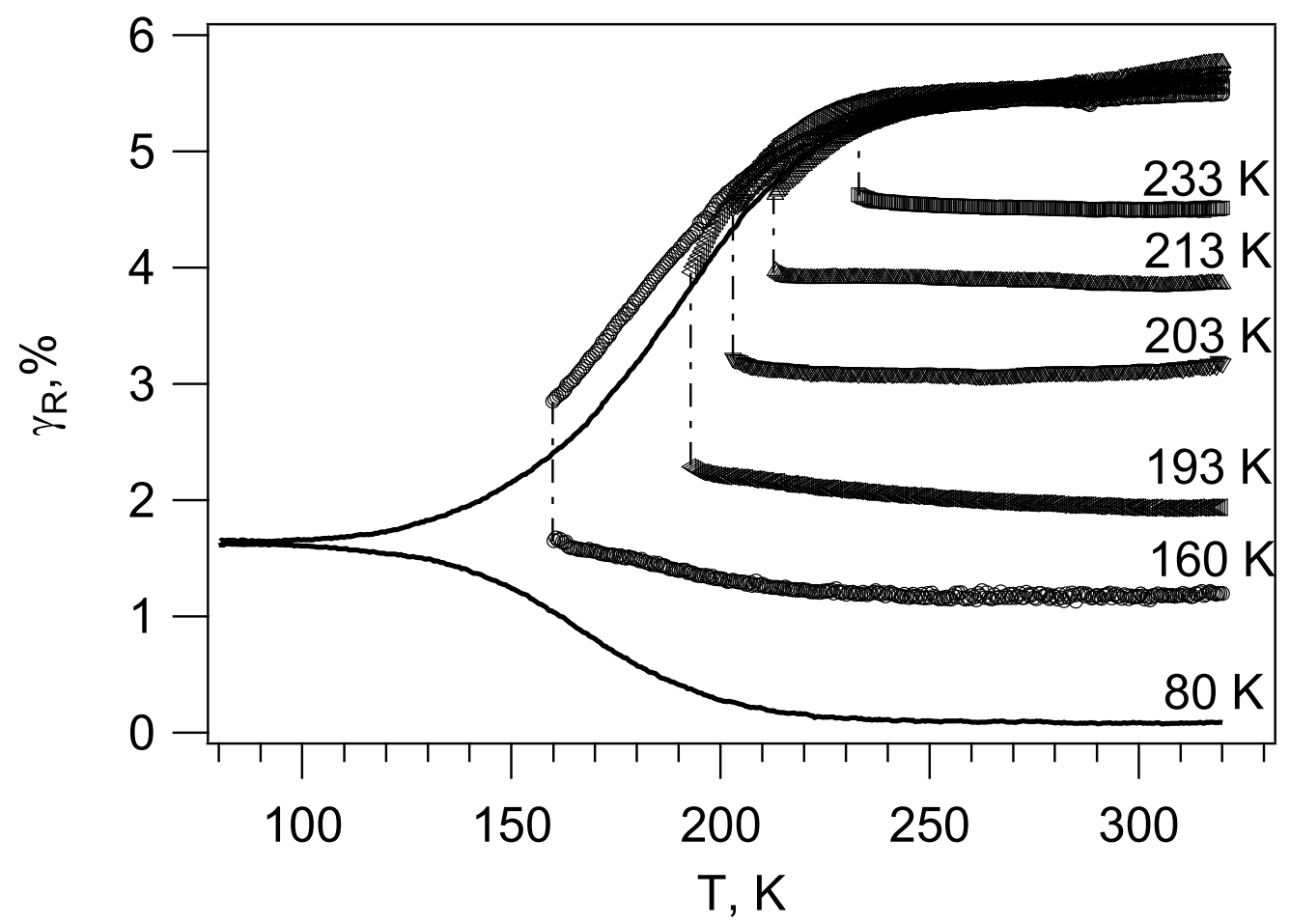

Figure 1b. Fraction of retained austenite in AISI 52100 relative to the third cooling cycle to $80 \mathrm{~K}$. Isothermal transformations are given in Figure $2 \mathrm{~b}$. The upper curves are the cooling curves; the lower curves are the heating curves. 


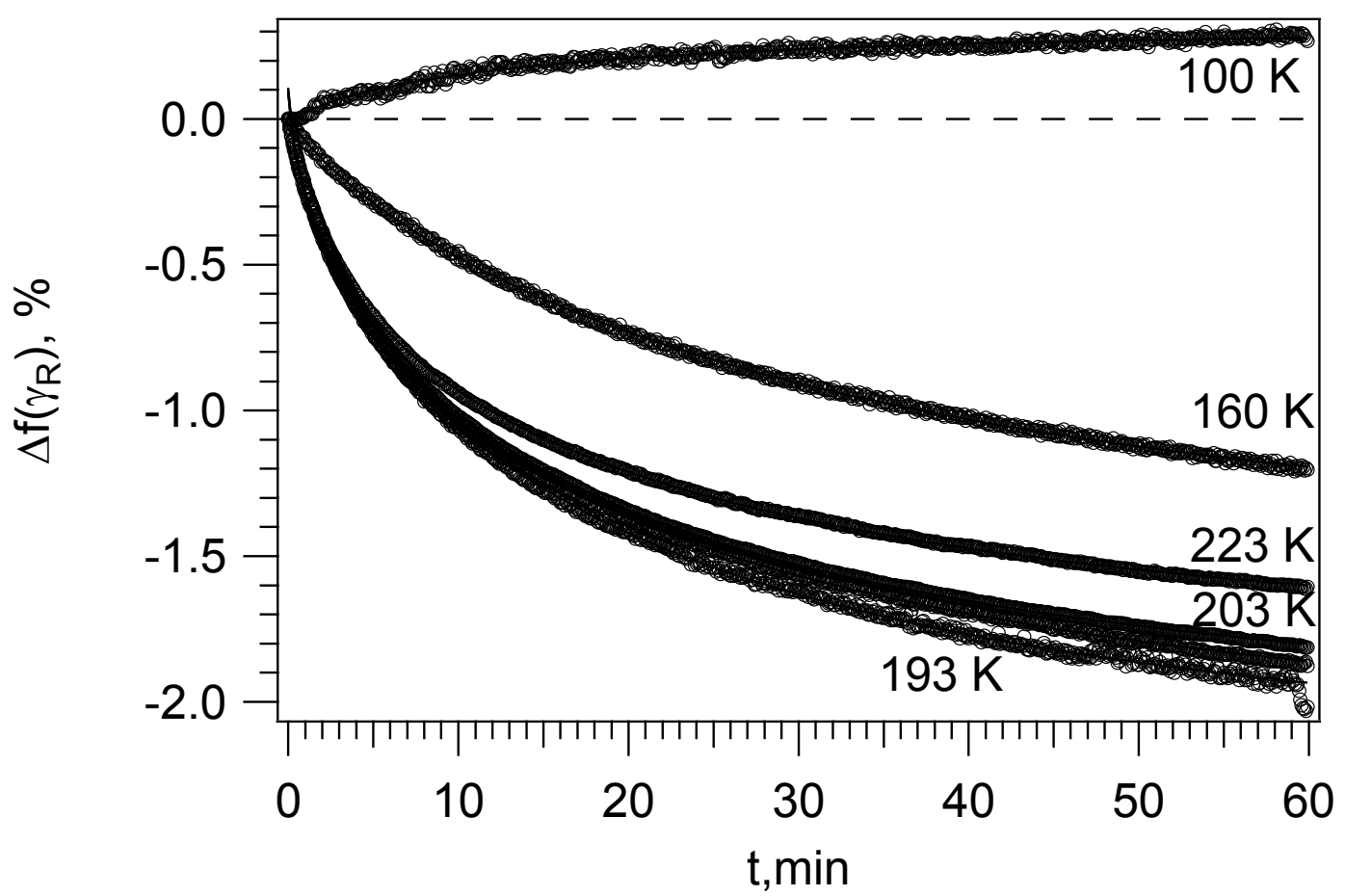

Figure 2a. AISI 1070. Change in content of retained austenite during isothermal holding at the temperatures indicated. The curve for $233 \mathrm{~K}$ lies in-between those for $193 \mathrm{~K}$ and $203 \mathrm{~K}$. All kinetic curves were excellently described by a JMAK equation (cf. Table 2).

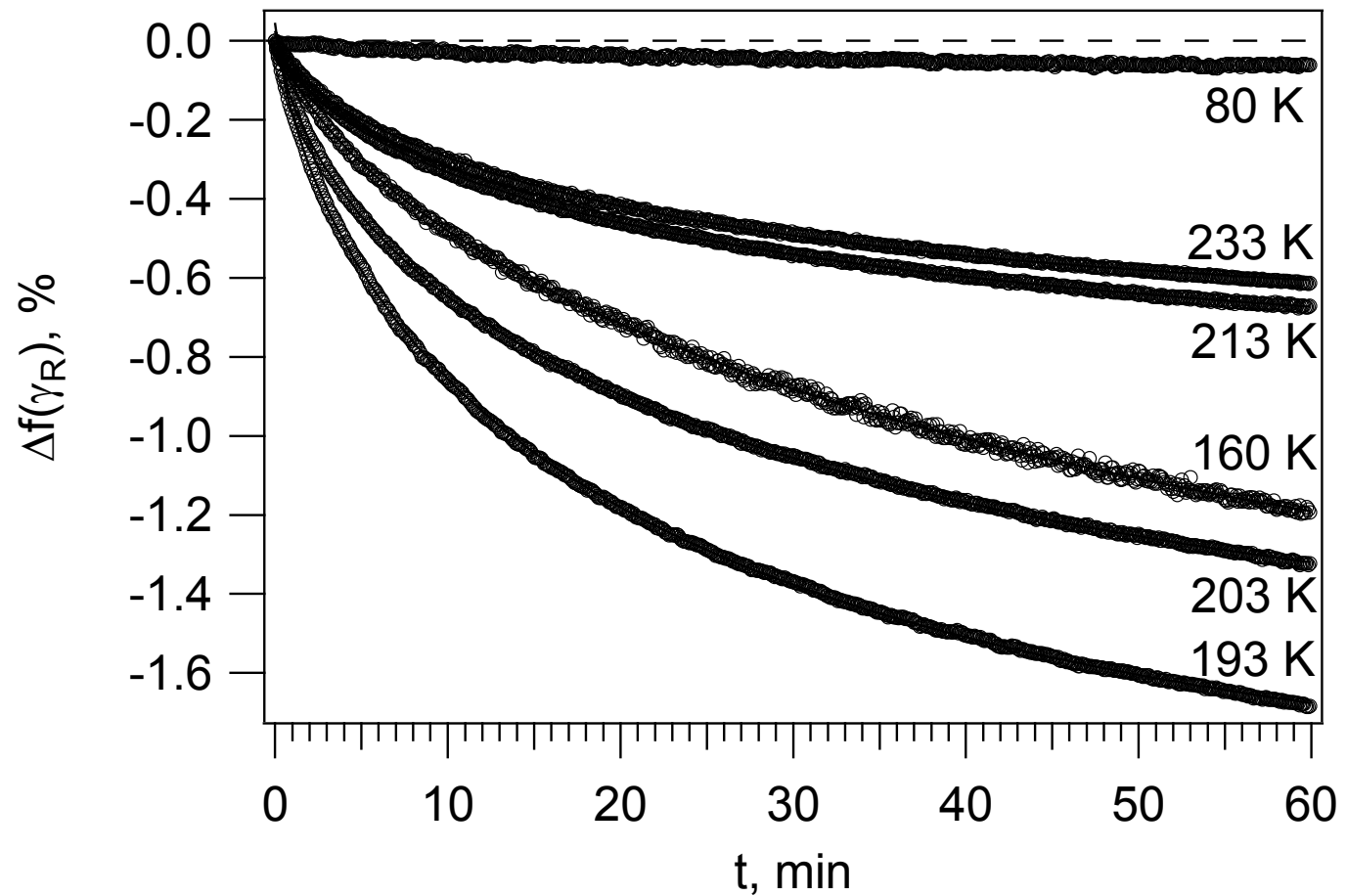

Figure 2b. AISI 52100. Change in content of retained austenite during isothermal holding as a function of time. Apart from $80 \mathrm{~K}$ all kinetic curves were excellently described by a JMAK equation (cf. Table 2). 


\subsection{Dilatometry}

The measured length increase of the samples during isothermal holding is shown in Fig. 3 for AISI 1070 LS and AISI E 52100. The length increases for AISI 1070 LS at $193 \mathrm{~K}$ and $223 \mathrm{~K}$ show the same trend as the VSM results in Fig.2a, i.e. a continuous increase of the sample length, indicating the transformation from austenite to martensite. As compared to Fig.2a the dilatometry results approach a stationary value faster than the VSM results. For the AISI E 52100 samples the length change shows an initial increase in sample length, followed by a contraction of the sample on continued isothermal holding. As a result a maximum length increase is observed. The contraction is the larger, the lower the isothermal transformation temperature. The occurrence (in time) of this maximum length increase is observed after longer holding time the lower the holding temperature. This decrease of the sample length cannot be reconciled with continued martensitic transformation, unless the martensite develops in another direction than the measurement direction and causes a contraction in the measurement direction as a consequence.

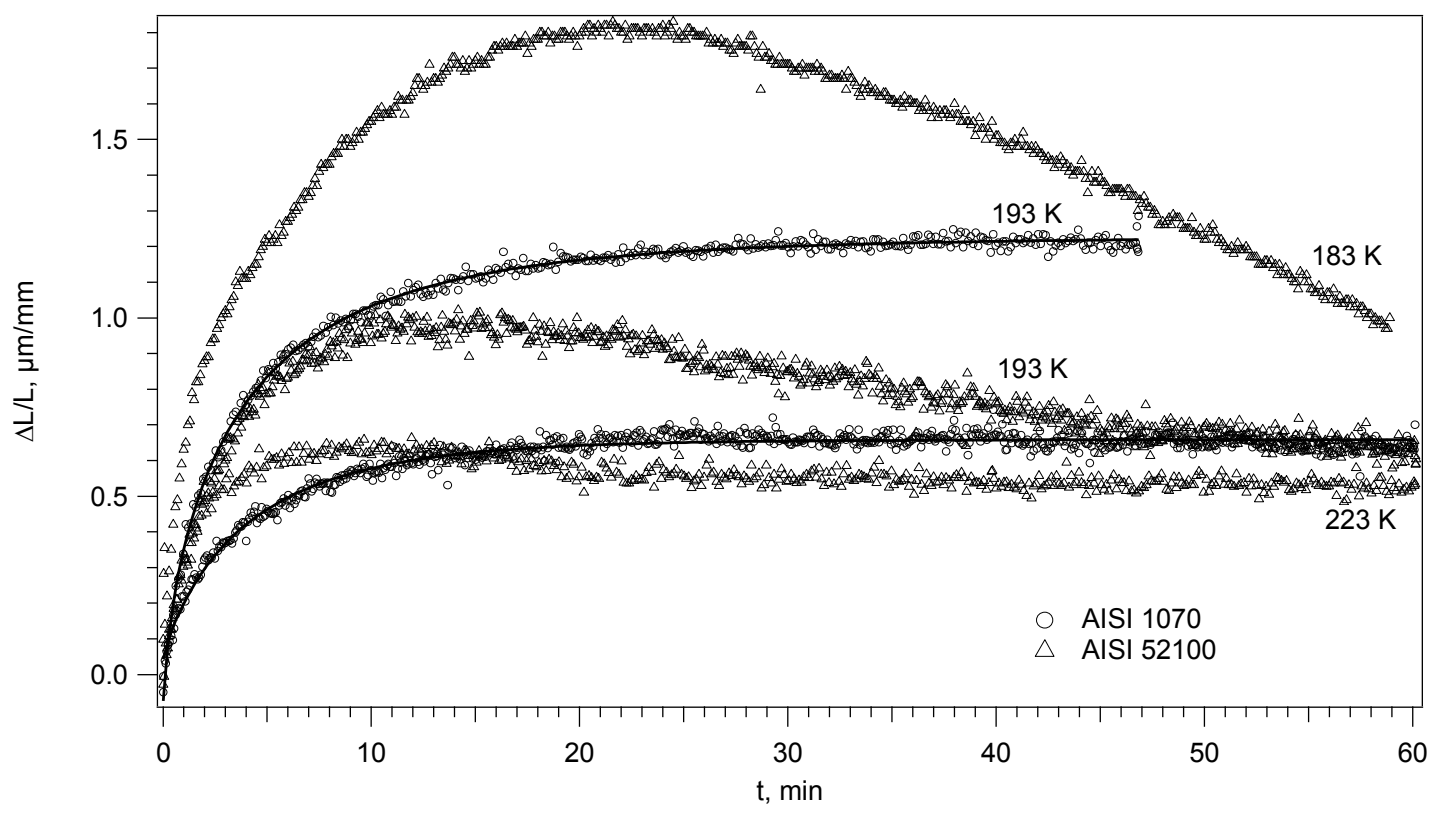

Figure 3. Length change during isothermal holding of AISI 1070 and 52100 at the temperatures indicated. Data for AISI 1070 were fitted with the JMAK equation in Eq.(2). The results at $183 \mathrm{~K}$ were determined with the Adamel dilatometer; all other results were obtained with the Bähr dilatometer.

\section{DISCUSSION}

The results obtained by Vibrating Sample Magnetometry (VSM) show unequivocally that retained austenite transforms into martensite on cooling to temperatures below a certain undercooling with respect to room temperature. It is assumed that this start temperature is observed, because the storage time of 30 minutes at room temperature before sub-zero cooling has enabled a stabilization of the martensite and austenite formed during quenching. Consequently, the continued transformation of retained austenite into martensite is first initiated at some undercooling below room temperature, because a new driving force has to be built up. 
Both VSM and dilatometry investigations show that the martensite development continues isothermally upon interrupting the continuous cooling cycle. This isothermal continuation of the transformation is not a consequence of the levelling out of temperature gradients in the sample. Even though the isothermal transformation at the temperature under consideration is not completed after 1 hour, it appears that it comes to halt soon after the onset of reheating. This effect is less pronounced on heating from temperatures below the maximum transformation rate $(169 \mathrm{~K})$.

From the VSM results it is clear that the degree of transformation is a function of the temperature to which the sample is cooled. The kinetic results, characterized by a continuously decreasing transformation rate with time, suggest that all nuclei were present on starting the isothermal transformation. This could be consistent with continued growth of martensite formed earlier. An attempt was made to describe the isothermal results by Johnson-Mehl-Avrami-Kolmogorov kinetics: ${ }^{[14]}$

$$
f=1-\exp \left(-\beta^{n}\right)
$$

where $n$ is the order of the transformation, $\beta=k(T) . t$, with $k(T)$ a temperature $(T)$ dependent reaction rate constant, obeying an Arrhenius type expression $k=k_{o} \exp \left\{-\frac{E_{a}}{R T}\right\}$ with $E_{a}$ the activation energy for the transformation. Eq. (2) was fitted to the isothermal curves in the following form $f=a+b\left(1-\exp \left(-(k \cdot t)^{n}\right)\right)$ where $a$, $b, k$ and $n$ were taken as fit parameters. The purpose of $a$ and $b$ is to take a deviation from a zero baseline and the normalization of the data to $0<f<1$ into account. Generally, excellent convergence of the fits was obtained; the standard deviation of the fitted $n$ and $k$ values is typically less than $1 \%$. The fitted curves are included in Fig.2 but cannot be distinguished from the data points. The values obtained for the kinetic parameters $k$ and $n$ are given in Table 2. No convergence of the fits was obtained at $80 \mathrm{~K}$ and $100 \mathrm{~K}$ for 52100 and 1070, respectively.

Table 2. Kinetic coefficients $n$ and $k$ obtained by fitting Eq.(2) to the isothermal transformation curves in Fig.2

\begin{tabular}{ccc|ccc}
\hline \multicolumn{3}{c|}{ AISI 1070} & \multicolumn{3}{c}{ AISI 52100 } \\
\hline $\mathrm{T}, \mathrm{K}$ & $\mathrm{k}$ & $\mathrm{n}$ & $\mathrm{T}, \mathrm{K}$ & $\mathrm{k}$ & $\mathrm{n}$ \\
\hline 160 & 0.0327 & 0.808 & 160 & 0.0195 & 0.679 \\
193 & 0.0570 & 0.633 & 193 & 0.0462 & 0.645 \\
203 & 0.0600 & 0.616 & 203 & 0.0339 & 0.621 \\
223 & 0.0631 & 0.570 & 213 & 0.0359 & 0.623 \\
233 & 0.0545 & 0.597 & 233 & 0.0361 & 0.616 \\
\hline
\end{tabular}

The kinetic parameters in Table 2 show that the values of $n$ are in the range 0.57-0.81 (average: 0.64) and tend to decrease with increasing transformation temperature. The $n$ values determined would be consistent with the diffusion controlled thickening of plates $(n=1 / 2)$ or needles $(n=1)$ after complete impingement. ${ }^{[15]}$ Since martensitic transformations are by definition diffusionless, it is suggested that diffusion controlled phenomena in the matrix surrounding the transforming region are rate determining for the growth of martensite. Qualitatively, the trend of a decreasing $n$ value with increasing transformation temperature could be explained from a change of the shape of the growing particles. The lower the transformation temperature the 
more martensite has developed during cooling to the temperature where isothermal transformation is observed. Thus, the present isothermal results are consistent with the growth of existing martensite laths and plates and indicate that the higher the temperature where isothermal continuation of martensite formation is investigated, the smaller are the (athermally formed) nuclei that grow. This might imply that no new nuclei develop on continued cooling. The thermally activated nature of the continued martensite development could be associated with a redistribution of point defects in austenite ahead of the growing martensite, e.g. vacancies, leading to strain relaxation. In principle, the temperature dependence of the $k$ values does not obey Arrhenius dependence for the present case, because samples with different initial contents of martensite were investigated for the different temperatures (which also cause the variation in $n$ ). Evaluating the scattered $k$ values in terms of an Arrhenius dependence yields values of about 2-3 $\mathrm{kJ}^{\mathrm{mol}}{ }^{-1}$ for both steels.

From dilatometry, the progress of the martensitic transformation is also observed. For the AISI 1070 steel the fitted coefficients $n$ are 0.626 and 0.821 for $223 \mathrm{~K}$ and $193 \mathrm{~K}$ respectively, and are systematically higher than the values in Table 2 for the same temperatures. For the AISI E 52100 series two mechanisms are contributing simultaneously, which implies that Eq.(2) can be fitted only up to 10-20 minutes, where the length increase dominates. It is believed that strain relaxation occurring simultaneously with martensite formation causes the contraction upon continued transformation. Strain relaxation could be consistent with growth of martensite, which is rate controlled by a thermally activated mechanism in the surroundings. Apparently micro-plastic, creep-like mechanisms are active at the low temperatures under consideration.

The austenite-to-martensite transformation on reheating from the lowest reached temperature (cf. Figs.1) indicates that new martensite develops even though the driving force decreases (on heating). These results can be understood along the same lines as sketched above. The continued martensite development requires stress relaxation, irrespective of whether new nuclei develop or growth of previously formed nuclei occurs. Evidently, below a certain temperature stress relaxation is no longer possible at a rate that allows the observation of an actual transformation, despite an enhanced driving force. This could be consistent with thermally activated stress relaxation as provided by creep-like micro-plastic mechanisms.

\section{CONCLUSIONS}

On sub-zero treatment of AISI 1070 LS and AISI E52100 martensite was observed to develop during cooling, on heating from a low temperature $(<193 \mathrm{~K})$ as well as during isothermal holding. These observations indicate that parameters of cryogenic treatment as cooling rate, heating rate as well holding time and temperature are likely to have an influence on the properties obtained after sub-zero treatment.

An investigation of the kinetics of martensite formation during isothermal holding after cooling, shows that the results obtained with vibrating sample magnetometry can be described quantitatively by JMAK kinetics, where the fitted JMAK coefficient would be consistent with the growth of plates or laths, i.e. $n=1 / 2-1$. For higher temperatures $\mathrm{n}$ approaches $1 / 2$, indicating that the growing martensite plates are thinner (more lath type) than at lower isothermal transformation temperatures.

Dilatometry indicates that stress relaxation occurs on continued isothermal transformation. Stress relaxation can be accomplished by a thermally activated 
creep-like micro-plasticity mechanism, operational already at cryogenic temperatures.

\section{Acknowledgement}

The work was financed by the Danish Research Council (STVF) under grant 26-01-0174.

\section{REFERENCES}

1 Collins, D.N., Dormer, J.: Heat Treatment of Metals vol. 3, 1997, p. 71-74.

2 Barron, R.F.: Cryogenics, August, 1982, p. 409-413.

3 Cheng, L., Brakman, C.M., Korevaar, B.M., Mittemeijer, E.J.: Metall. Trans. A, vol. 19A, 1988, pp. 2415-2426.

4 Yun, D., Xiaoping, L., Hongshen, X.: Heat Treatment of Metals vol. 3, 1998, pp. $55-59$.

5 Mahmudi, R., Ghasemi, H.M., Faradji, H.R.: Heat Treatment of Metals vol. 3, 2000, pp. $69-72$.

6 Yen, P-L., Kammody, D.: Industrial Heating, January, 1997, pp. 40 - 44.

7 Lal, D.M., Renganarayanan, S., Kalanidhi, A.: Cryogenics vol. 41, 2001, pp. $149-155$.

8 Molinari, A., Pelizzari, M., Gianella, S., Straffelini, G., Stiasny, K.H.: J. of Materials Processing Technology 118, 2001, pp. 350-355.

9 Meng, F., Tagashira, K., Sohma, H.: Scripta Metall. Vol. 31 no. 7, 1994, pp. 865-868.

10 Hsu, T.Y., Yexin, C., Weiye, C.: Metall. Trans. A 18A, 1987, pp. 1389-1394.

11 Wierszyllowski, I.A.: J. Phys. IV France 7, 1997, (C5) pp. 417-422.

12 N.N. Thadhani, M.A. Meyers: Prog. Mater. Sci. Vol.30, 1986, pp. 1-37.

13 Stojko, A.: PhD thesis, Technical University of Denmark, 2006.

14 Mittemeijer, E.J.: J. Mater. Sci. Vol. 27, 1992, pp. 3977-3987.

15 Christian, J.W.: The theory of transformations in Metals and Alloys, Pergamon, 2002, p. 546. 